\title{
Image (Pre-image) Homomorfisme Interior Subgrup Fuzzy
}

\author{
Saman Abdurrahman \\ Program Studi Matematika FMIPA Universitas Lambung Mangkurat, JI. A. Yani Km 36 Banjarbaru \\ Kalimantan Selatan 70714, Indonesia. \\ Korespondensi; Email: saman@ulm.ac.id
}

\begin{abstract}
Abstrak
Dalam makalah ini, akan diperkenalkan notasi image (pre-image) di bawah homomorfisma grup, dan akan dibuktikan image (pre-image) interior subgrup fuzzy (interior subgrup) di bawah homomorfisma grup selalu interior subgrup fuzzy (interior subgrup).
\end{abstract}

Kata Kunci: Image; pre-image; interior subgrup; interior subgrup fuzzy; homomorfisma grup

\begin{abstract}
In this paper, we will introduce the image (pre-image) under the group homomorphism, and we will prove the image (pre-image) of the interior of the fuzzy subgroup (the interior of the subgroup) under the group homomorphism is always the interior of the fuzzy subgroup (the interior of the subgroup).
\end{abstract}

Keywords: Image; pre-image; interior subgroup; fuzzy interior subgroup; group homomorphism

\section{Pendahuluan}

Setelah himpunan fuzzy dipublikasikan Zadeh (Zadeh, 2015), beberapa peneliti mengeksplorasi gagasan himpunan fuzzy, diantaranya Rosenfeld (Rosenfeld, 1971) menerapkannya pada teori dasar grupoid dan grup sehingga muncul definisi grupoid fuzzy dan subgrup fuzzy, Kuroki (Kuroki, 1982) menerapkannya pada struktur semigrup dan mendefinisikan semigrup fuzzy dan interior ideal fuzzy pada semigrup, Jeyaraman (Jeyaraman, 2010) menerapkannya pada homomorfisma dan anti homomorfisma grup, dan Abdurrahman[5] mendefinisikan interior subgrup fuzzy yang diinduksi dari definisi yang dibangun Kuroki (Kuroki, 1982).

Pada makalah ini, akan diperkenalkan definisi image dan pre-image dari interior subgrup fuzzy di bawah suatu homomorfisma grup, dan akan menyelidiki sifat dari image dan pre-image dari interior subgrup fuzzy (interior subgrup) jika dikenakan suatu homomorfisma grup.

\section{Landasan Teori}

Suatu Himpunan $G$ tidak kosong (Hotta, 2018) disebut sebagai grup, jika pada $G$ diberikan suatu operasi biner, dan elemen-elemen pada $G$ terhadap operasi biner tersebut dipenuhi sifat asosiatif, memuat elemen identitas, dan setiap elemen mempunyai invers. Lebih lanjut (Lal, 2017) subset tidak kosong $S$ dalam $G$ disebut subgrup jika untuk setiap $a, b \in S$ dipenuhi $a b^{-1} \in S$.

Definisi 2.1. (Mordeson, 2011; Ajmal \& Jahan, 2012; Talebi, 2018) Subset fuzzy dari himpunan tidak kosong $X$ didefinisikan sebagai suatu fungsi dari $X$ ke interval tutup $[0,1]$. Selanjutnya keluarga subset fuzzy dari $X$ dinotasikan dengan $\mathbb{F}(X)$. 
Definisi 2.2. (Das, 1981) Misalkan $\delta$ adalah subset fuzzy dari $X$. Untuk $t \in[0,1]$, himpunan $\delta_{t}=:\{x \in X \mid \delta(x) \geq t\}$ disebut level subset dari subset fuzzy $\delta$.

Definisi 2.3. (Rosenfeld, 1971; Ajmal \& Jahan, 2012; Bejines et al, 2018) Subset fuzzy $\delta$ dari suatu grup $G$ merupakan subgrup fuzzy dari $G$ jika untuk setiap $x, y \in G$ berlaku $\delta(x y) \geq \min \{\delta(x), \delta(y)\}$, dan $\delta\left(x^{-1}\right) \geq \delta(x)$.

Definisi 2.4. (Jeyaraman, 2010; Kim \& Kim, 1996) Misalkan $\delta \in \mathbb{F}(X)$ dan $\sigma \in \mathbb{F}(Y)$ dengan $f$ adalah fungsi dari $X$ ke $Y$. Didefinisikan subset fuzzy $f_{\delta} \in \mathbb{F}(Y)$ dan $f_{\sigma}^{-1} \in \mathbb{F}(X)$ berturut-turut sebagai berikut:

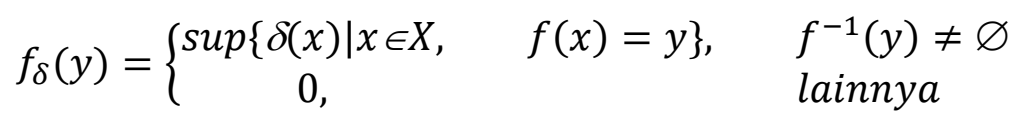

untuk setiap $y \in Y$, dan $f_{\sigma}^{-1}(x)=\sigma[f(x)]$ untuk setiap $x \in X$.

Selanjutnya $f_{\delta}$ disebut image dari $\delta$ di bawah $f$, dan $f_{\sigma}^{-1}$ disebut preimage dari $\sigma$ di bawah $f$.

Definisi 2.5. (Abdurrahman, 2018) Subgrup $H$ dari grup $G$ disebut interior dari $G$ jika untuk setiap $x, y \in G$ dan $h \in H$ maka $x h y \in H$.

Definisi 2.6. (Abdurrahman, 2018) Misalkan $G$ grup dan $\delta \in \mathbb{F}(G)$. Subset fuzzy $\delta$ adalah interior subgrup fuzzy dari $G$ jika $\delta$ adalah subgrup fuzzy dari $G$ dan $\delta(x d y) \geq \delta(d)$ untuk setiap $x, d, y \in G$.

\section{Hasil Analisis Data dan Pembahasan}

Teorema 3.1. Preimage homomorfisma grup dari suatu interior subgrup fuzzy adalah interior subgrup fuzzy.

Bukti: Misalkan $f: K \rightarrow H$ adalah suatu homomorfisma grup, dengan $\sigma$ adalah interior subgrup fuzzy di grup $H$, dan $f_{\sigma}^{-1}$ adalah preimage dari $\sigma$ di bawah $f$. Akan dibuktikan $f_{\sigma}^{-1}$ adalah interior subgrup fuzzy di grup $K$.

Diambil sebarang $p, q, k \in K$ maka

$$
\begin{aligned}
f_{\sigma}^{-1}\left(p q^{-1}\right) & =\sigma\left\{f\left(p q^{-1}\right)\right\} \\
& =\sigma\left\{f(p) f\left(q^{-1}\right)\right\} \\
& =\sigma\left\{f(p)[f(q)]^{-1}\right\} \\
& \geq \min \{\sigma[f(p)], \sigma[f(q)]\} \\
& =\min \left\{f_{\sigma}^{-1}(p), f_{\sigma}^{-1}(q)\right\},
\end{aligned}
$$

dan

$$
\begin{aligned}
f_{\sigma}^{-1}(p k q) & =\sigma[f(p k q)] \\
= & \sigma[f(p) f(k) f(q)] \\
\geq & \sigma[f(k)] \\
= & f_{\sigma}^{-1}(k) .
\end{aligned}
$$

Jadi, $f_{\sigma}^{-1}$ adalah interior subgrup fuzzy di grup $K$, dengan kata lain Preimage homomorfisma grup dari suatu interior subgrup fuzzy adalah interior subgrup fuzzy.

Berikut ini diberikan definisi subset fuzzy yang mempunyai sifat sup, yang akan mendukung pada pembuktian teorema berikutnya. 
Definisi 3.2. (Kumar, 1991) Subset fuzzy $\delta$ pada suatu grup $G$ dikatakan mempunyai sifat sup, jika untuk setiap subset $H$ dari $G$, terdapat $h_{0} \in H$ sedemikian hingga $\delta\left(h_{0}\right)=\sup _{h \in H} \delta(n)$

Teorema 3.3. Image homomorfisma grup dari suatu interior subgrup fuzzy dengan sifat sup adalah interior subgrup fuzzy.

Bukti: Misalkan $K$ dan $H$ adalah grup, dan $f: K \rightarrow H$ adalah suatu homomorfisma grup, dengan $\delta$ adalah interior subgrup fuzzy di $K$ dengan sifat sup, dan $f_{\delta}$ adalah image dari $\delta$ di bawah $f$. Akan dibuktikan $f_{\delta}$ adalah interior subgrup fuzzy di $H$.

Diambil sebarang $a, b, c \in f(K)$, maka ada $a_{0}, b_{0}, c_{0} \in K$ sedemikian hingga $a_{0}=f^{-1}(a), b_{0}=f^{-1}(b)$, dan $c_{0}=f^{-1}(c)$ dengan

$$
\delta\left(a_{0}\right)=\sup _{d \in f^{-1}(a)} \delta(d), \quad \delta\left(b_{0}\right)=\sup _{d \in f^{-1}\left(b_{0}\right)} \delta(d), \quad \operatorname{dan} \delta\left(c_{0}\right)=\sup _{d \in f^{-1}(c)} \delta(d)
$$

Menurut yang diketahui $f_{\delta}$ adalah image dari $\delta$ di bawah $f$, maka

$$
\begin{aligned}
f_{\delta}\left(a c^{-1}\right) & =\sup _{d \in f^{-1}\left(a c^{-1}\right)} \delta(d) \\
& \geq \delta\left(a_{0} c_{0}^{-1}\right) \\
& \geq \min \left\{\delta\left(a_{0}\right), \delta\left(c_{0}\right)\right\} \\
& =\min \left\{\sup _{d \in f^{-1}(a)} \delta(d), \sup _{d \in f^{-1}(c)} \delta(d)\right\} \\
& =\min \left\{f_{\delta}(a), f_{\delta}(c)\right\},
\end{aligned}
$$

dan

$$
\begin{aligned}
f_{\delta}(a b c) & =\sup _{d \in f^{-1}(a b c)} \delta(d) \\
& \geq \delta\left(a_{0} b_{0} c_{0}\right) \\
& \geq \delta\left(b_{0}\right) \\
& =\sup _{d \in f^{-1}\left(b_{0}\right)} \delta(d) \\
& =f_{\delta}(b) .
\end{aligned}
$$

Jadi, $f_{\delta}$ adalah interior subgrup fuzzy di $H$.

Akibat 3.4. Image epimorfisma grup dari suatu interior subgrup fuzzy dengan sifat sup adalah interior subgrup fuzzy.

Lemma 3.5. Jika $f: G \rightarrow H$ adalah suatu epimorfisma grup, dan $\delta$ adalah interior subgrup fuzzy di $G$, maka image homomorfisma $\delta^{\star}=\left\{x \in G \mid \delta(x)=\delta\left(e_{G}\right)\right\}$ adalah interior subgrup di $H$.

Bukti: Mengingat $\delta$ adalah interior subgrup fuzzy di $G$, maka menurut Abdurrahman (Abdurrahman, 2018, Lemma 3.9), $\delta^{\star}$ adalah interior subgrup di $G$. Akan ditujukkan $f\left(\delta^{\star}\right)$ adalah interior subgrup di $H$.

Diambil sebarang $m, r \in f\left(\delta^{\star}\right)$ maka terdapat $a, c \in \delta^{\star}$ sedemikian hingga $f(a)=m$ dan $f(c)=r$. Karena $\delta^{\star}$ adalah subgrup di $G$, dan $f$ suatu homomorfisma, maka $a c^{-1} \in \delta^{\star}$ yang mengakibatkan $f\left(a c^{-1}\right) \in f\left(\delta^{\star}\right)$, yaitu $f\left(a c^{-1}\right)=f(a) f\left(c^{-1}\right)=f(a)[f(c)]^{-1}=m r^{-1}$, dengan kata lain $f\left(\delta^{\star}\right)$ adalah subgrup di $H$. Selanjutnya, diambil sebarang $x, s \in H$ dan $d \in f\left(\delta^{\star}\right)$. Mengingat $f$ suatu epimorfisma dan $\delta^{\star}$ adalah interior subgrup di $G$, maka ada $p, r \in G$ dan $q \in \delta^{\star}$, yaitu $x=f(p), d=$ $f(q), s=f(r)$, dan $p q r \in \delta^{\star}$ yang mengakibatkan $f(p q r)=f(p) f(q) f(r)=\operatorname{xds} \in f\left(\delta^{\star}\right)$.

Berdasarkan analisa di atas diperoleh lain $f\left(\delta^{\star}\right)$ adalah subgrup di $H$, dan $x d s \in f\left(\delta^{\star}\right)$ untuk setiap $x, s \in H$ dan $d \in f\left(\delta^{\star}\right)$, maka menurut Definisi $2.5, f\left(\delta^{\star}\right)$ interior subgrup di $H$. 
Lemma 3.6. Jika $f: G \rightarrow H$ adalah suatu homomorfisma grup, dan $\sigma$ adalah interior subgrup fuzzy di $H$, maka pre-image homomorfisma $\sigma^{\star}=\left\{h \in H \mid \sigma(h)=\sigma\left(e_{H}\right)\right\}$ adalah interior subgrup di $G$.

Bukti: Pembuktian $\sigma^{\star}$ adalah interior subgrup di $H$, sejalan dengan bukti Teorema 3.5. Akan ditujukkan $f^{-1}\left(\sigma^{\star}\right)$ adalah interior subgrup di $G$.

Diambil sebarang $a$ dan $z$ di $f^{-1}\left(\sigma^{\star}\right)$, maka ada $b, w \in \sigma^{\star}$ sedemikian hingga $f(a)=b$ dan $f(z)=$ $w$. Mengingat $\sigma^{\star}$ merupakan subgrup di $H$, dan $f$ suatu homomorfisma, maka $b w^{-1} \in \sigma^{\star}$ yang mengakibatkan $b w^{-1}=f(a)[f(z)]^{-1}=f(a) f\left(z^{-1}\right)=f\left(a z^{-1}\right) \Leftrightarrow a z^{-1} \in f^{-1}\left(b w^{-1}\right)$.

Dengan kata lain $f^{-1}\left(\sigma^{\star}\right)$ adalah subgrup di $G$.

Selanjutnya, diambil sebarang $b, n \in G$ dan $z \in f^{-1}\left(\sigma^{\star}\right)$, maka $f(b), f(n) \in \mathrm{H}$ dan $f(z) \in \sigma^{\star}$. Mengingat $\sigma^{\star}$ adalah interior subgrup di $\mathrm{H}$, dan $f$ suatu homomorfisma, maka

yang mengakibatkan $f^{-1}\left(\sigma^{\star}\right)$ adalah interior subgrup di $G$.

\section{Kesimpulan}

Hasil penting yang dapat dijadikan sebuah kesimpulan dari tulisan ini adalah, image dan pre-image homomorfisma grup dari interior subgrup fuzzy (interior grup) adalah interior subgrup fuzzy (interior grup).

\section{Referensi}

[1] L. A. Zadeh, 2015, Fuzzy logic - A personal perspective, Fuzzy Sets Syst., vol. 281, pp. 420.

[2] A. Rosenfeld, 1971. Fuzzy groups, J. Math. Anal. Appl., vol. 35, no. 3, pp. 512517.

[3] N. Kuroki, 1982, Fuzzy Semiprime Ideals in Semigroup, Fuzzy Sets Syst., vol. 8, no. 1, pp. 7179.

[4] K. Jeyaraman, 2010. The Homomorphism and Anti-Homomorphism of Level Subgroups of Fuzzy Subgroups, Int. Math. Forum, vol. 5, no. 46, pp. 22932298.

[5] S. Abdurrahman, 2018, Interior Subgrup Fuzzy, J. Fourier, vol. 7, no. 1, pp. 1321.

[6] S. Hotta, 2018, Introductory Group Theory, in Mathematical Physical Chemistry: Practical and Intuitive Methodology, Singapore: Springer Singapore, pp. 445456.

[7] R. Lal, 2017. Group Theory, in Algebra 1: Groups, Rings, Fields and Arithmetic, Singapore: Springer Singapore, pp. 93143.

[8] J. N. Mordeson, 2011. Zadehs influence on mathematics, Sci. Iran., vol. 18, no. 3 D, pp. 596601.

[9] N. Ajmal and I. Jahan, 2012, A study of normal fuzzy subgroups and characteristic fuzzy subgroups of a fuzzy group, Fuzzy Inf. Eng., vol. 4, no. 2, pp. 123143.

[10] A. A. Talebi, 2018, Cayley fuzzy graphs on the fuzzy groups, Comput. Appl. Math., pp. 122.

[11] P. S. Das, 1981. Fuzzy groups and level subgroups, J. Math. Anal. Appl., vol. 84, no. 1, pp. 264269.

[12] C. Bejines, M. Jesus Chasco, J. Elorza, and S. Montes, 2018, On the Preservation of an Equivalence Relation Between Fuzzy Subgroups, vol. 641, pp. 159167.

[13] S. D. Kim and H. S. Kim, 1996. On Fuzzy Ideals of Near-Ring, Bull Korean Math. Soc, vol. 33, no. 4, pp. 593601.

[14] R. Kumar, 1991, Homomorphisms and fuzzy (fuzzy normal) subgroups, Fuzzy Sets Syst., vol. 44, no. 1, pp. 165168. 